02

\title{
Ап-конверсия инфракрасного излучения в щелочно-земельных фторидах, активированных $\mathrm{Er}^{3+}$
}

\author{
(C) Е.А. Раджабов, Р.Ю. Шендрик \\ Институт геохимии им. А.П. Виноградова Сибирского отделения РАН, \\ 664033 Иркутск, Россия \\ e-mail: eradzh@igc.irk.ru
}

Поступила в редакцию 22.01.2020 г.

В окончательной редакции 30.07.2020 г.

Принята к публикации 03.08.2020 г.

\begin{abstract}
Изучены процессы ап-конверсии в кристаллах $\mathrm{MeF}_{2}-\mathrm{ErF}_{3}(\mathrm{Me}-\mathrm{Ca}, \mathrm{Sr}, \mathrm{Ba})$ в интервале концентраций $\mathrm{ErF}_{3}$ от 0.01 до $10 \mathrm{~mol} \%$ при возбуждении в инфракрасных полосах иона $\mathrm{Er}^{3+}$ излучением лазерных диодов 808, 978, $1542 \mathrm{~nm}$. При возбуждении $\lambda=1542 \mathrm{~nm}$ в спектре свечения $\mathrm{MeF}_{2}-\mathrm{Er}$ преобладает полоса ${ }^{4} I_{11 / 2}-{ }^{4} I_{15 / 2}$ при $990 \mathrm{~nm}$, вклад полос в видимой области спектра составляет менее 0.1. Энергетический выход ап-конверсионного свечения $\mathrm{MeF}_{2}-10 \% \mathrm{ErF}_{3}$ при возбуждении $1542 \mathrm{~nm}$ с плотностью мощности около $1 \mathrm{~W} / \mathrm{cm}^{2}$ находится в интервале от 14 до $26 \%$.
\end{abstract}

Ключевые слова: ап-конверсия, щелочно-земельные фториды, инфракрасное излучение.

DOI: $10.21883 /$ OS.2020.11.50164.10-20

\section{Введение}

Поиск эффективных люминофоров, преобразующих ближнее инфракрасное излучение с длиной волны $1-2 \mu \mathrm{m}$ в свет с длиной волны менее $1 \mu \mathrm{m}$, остается актуальной задачей. Ион $\mathrm{Er}^{3+}$ в кристаллах характеризуется сильным поглощением в области $1.4-1.6 \mu \mathrm{m}$, что открывает возможности повышения эффективности кремниевых солнечных батарей за счет регистрации излучения с энергией фотонов меньше ширины запрещенной зоны кремния [1].

Ионы $\mathrm{Er}^{3+}$ имеют подходящую для ап-конверсии систему электронных уровней и часто используются в паре с ионами $\mathrm{Yb}^{3+}$ во многих кристаллических и стеклообразных матрицах [2]. Впервые зеленые и красные полосы свечения $\mathrm{Er}^{3+}$ в кристаллах $\mathrm{BaF}_{2}-5 \%$ $\mathrm{ErF}_{3}$ при возбуждении в инфракрасной области обнаружены в работах Овсянкина и Феофилова [3-5] и интерпретированы как возникающие при двухфотонном $(\sim 980 \mathrm{~nm})$ и трехфотонном $(\lambda>1200 \mathrm{~nm})$ поглощении. $\mathrm{B} \mathrm{CdF}_{2}-\mathrm{ErF}_{3}$ интенсивность зеленой и красной полос свечения кубично увеличивалась с ростом интенсивности возбуждающего света [6,7]. Интенсивность зеленого свечения $\mathrm{BaF}_{2}-\mathrm{Er}^{3+}$ увеличивалась как квадрат концентрации эрбия в интервале 0.5-8\% при возбуждении в интервале 0.9-1.2 $\mu \mathrm{m}$, что интерпретировано как последовательное поглощение двух фотонов ионом эрбия [4].

Помимо видимых полос свечения, возбуждение лазерным излучением $1.5 \mu$ m приводит к появлению свечения в области $990 \mathrm{~nm}\left(\mathrm{CdF}_{2}-\mathrm{Er}[6], \mathrm{CaF}_{2}-\mathrm{Er}\right.$ [8]), интенсивность которого превышает интенсивности видимых полос. По этой причине некоторые фторидные материалы предлагались для повышения выхода кремниевых фотопреобразователей $[1,8,9]$.
Целью наших исследований являлась изучение механизмов и измерение энергетического выхода апконверсии в кристаллах щелочно-земельных фторидов $\mathrm{MeF}_{2}-\mathrm{Er}$ при возбуждении в инфракрасных полосах поглощения ионов $\mathrm{Er}^{3+}$.

\section{Методика эксперимента}

Кристаллы $\mathrm{MeF}_{2}(\mathrm{Me}-\mathrm{Ca}, \mathrm{Sr}, \mathrm{Ba})$ выращивались методом Стокбаргера в шестиствольном графитовом тигле в вакууме [10]. Несколько процентов $\mathrm{CdF}_{2}$ добавлялось в сырье для очистки шихты от кислородных примесей. Были выращены кристаллы щелочно-земельных фторидов с $\mathrm{ErF}_{3}$ (вводимая концентрация 0.01-10 mol.\%), а также кристаллы с двойной активацией $\mathrm{ErF}_{3}-\mathrm{YbF}_{3}$. В ряде кристаллов некоторая доля ионов $\mathrm{Yb}^{3+}$ (около 10\%) при выращивании преобразовывалась в двухвалентную форму.

Для возбуждения антистоксовой люминесценции использовались полупроводниковые лазерные диоды с длиной волны излучения 808, 978 и $1542 \mathrm{~nm} \mathrm{c} \mathrm{из-}$ меренными мощностями 400, 69 и $5 \mathrm{~mW}$. Мощность лазерного излучения измерялась с помощью ИМО-2М. Спектры поглощения в области 190-3000 nm измерялись на спектрофотометре Perkin-Elmer Lambda-950. Спектры свечения в области 200-890 nm измерены с использованием фотомодуля Hamamatsu H6780-04. Спектры свечения в длинноволновой области измерялись охлаждаемым фотоумножителем ФЭУ83, фотоприемным устройством с охлаждаемым Ge-фотодиодом ФПУФДГ ЛОМО-ФОТОНИКА (до $1700 \mathrm{~nm}$ ) и охлаждаемым фотосопротивлением PbS-ФСВ19AА (до $2500 \mathrm{~nm}$ ). Излучение регистрировалось через дифракционные монохроматоры МДР-2 и СДЛ-1 (ЛОМО). 
Энергетический выход ап-конверсии щелочно-земельных фторидов измерен с помощью интегрирующей сферы. Приемником излучения являлся кремниевый фотодатчик TSL237 с диапазоном чувствительности 300-1100 nm. Интенсивность возбуждающего пучка измерялась как с помощью сферы, так и с помощью термопарного измерителя мощности лазерного излучения ИМО-2М. Диаметр лазерного пучка диода $1542 \mathrm{~nm}$ оценивался методом „ножа“ (knife-edge method) [11]. Для этого интенсивность лазерного излучения измерялась германиевым фотодиодом при постепенном перекрытии пучка одной из сторон щели от монохроматора.

\section{Результаты}

В спектрах люминесценции кристаллов $\mathrm{MeF}_{2}-\mathrm{Er}^{3+}$ при возбуждении $405 \mathrm{~nm}$ наблюдались наиболее интенсивные полосы $\mathrm{Er}^{3+}$ при $550 \quad\left({ }^{4} S_{3 / 2}-{ }^{4} I_{15 / 2}\right)$, $660 \quad\left({ }^{4} F_{9 / 2}-{ }^{4} I_{15 / 2}\right), \quad 980 \quad\left({ }^{4} I_{11 / 2}-{ }^{4} I_{15 / 2}\right) \quad$ и $\quad 1550 \mathrm{~nm}$ $\left({ }^{4} I_{13 / 2}-{ }^{4} I_{15 / 2}\right)$ с развитой структурой вследствие взаимодействия с кристаллическим полем (для $\mathrm{SrF}_{2}-\mathrm{Er}^{3+}$
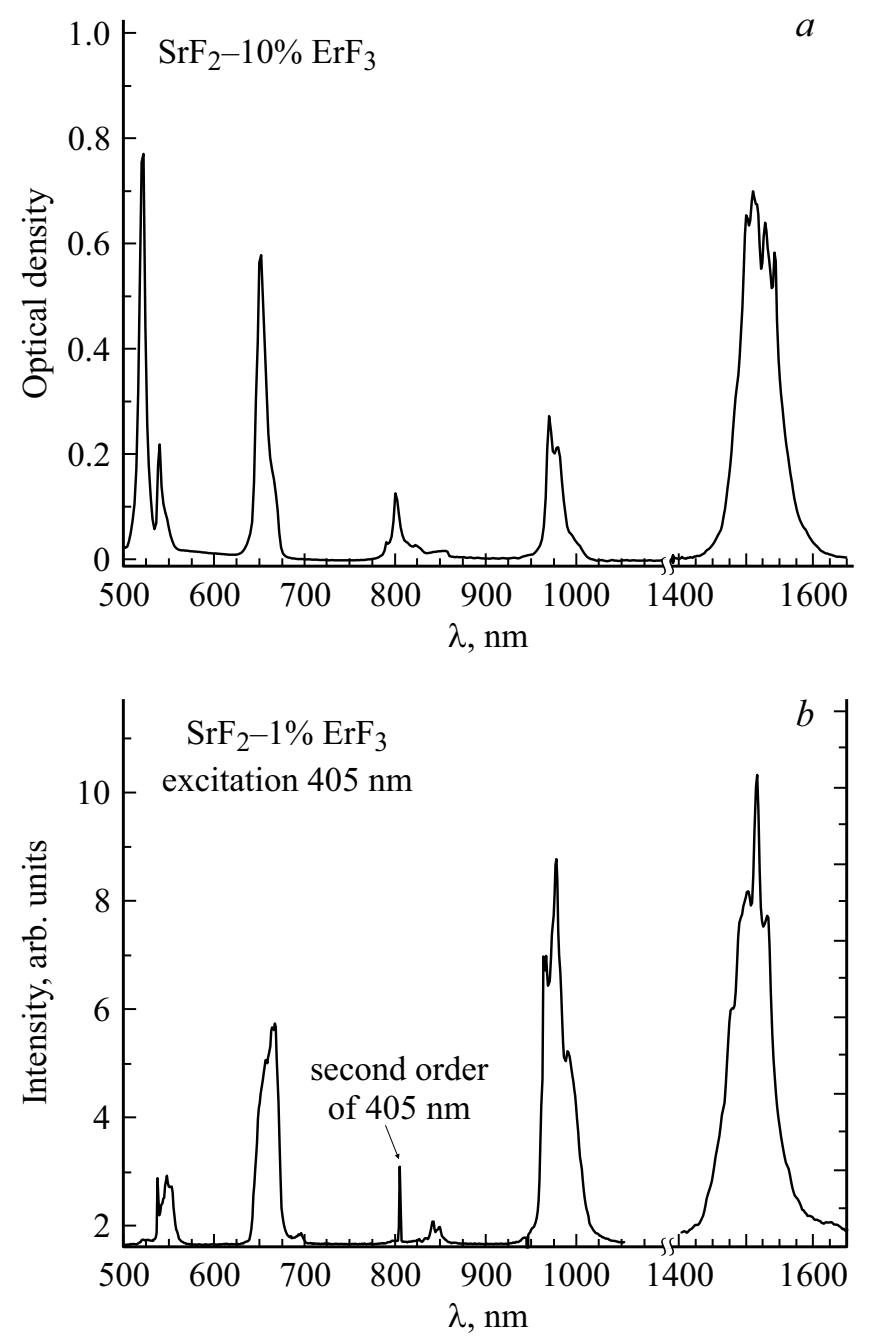

Pис. 1. Спектры поглощения $(a)$ и свечения $(b)$ кристаллов $\mathrm{SrF}_{2}-\mathrm{Er}^{3+}$ при комнатной температуре $(\mathrm{d}=1.65) \mathrm{mm}$.
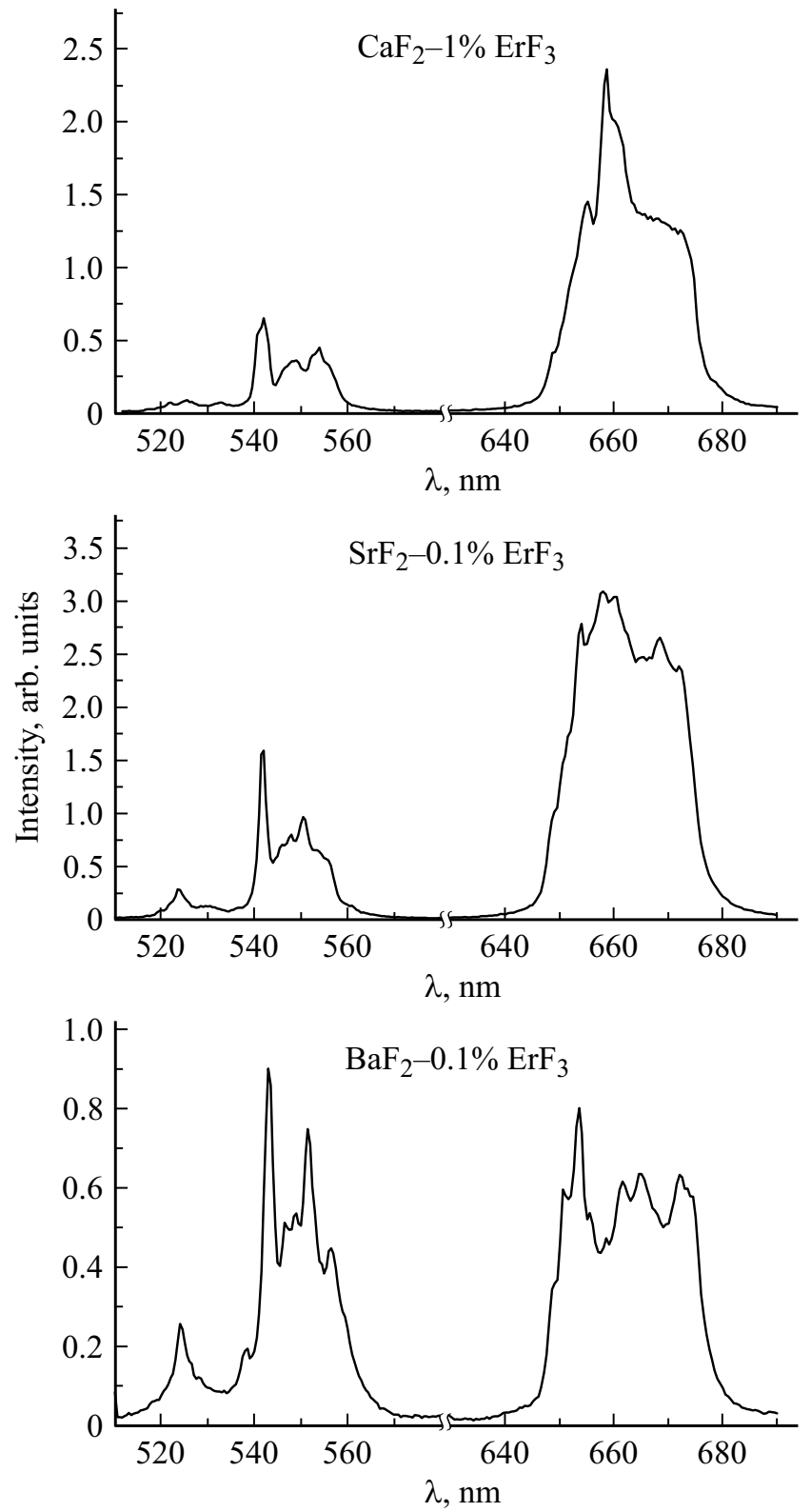

Рис. 2. Спектры свечения кристаллов щелочно-земельных фторидов $\mathrm{MeF}_{2}-0.1 \% \mathrm{ErF}_{3}$ при комнатной температуре при возбуждении $980 \mathrm{~nm}$.

рис. $1, b)$. Все полосы свечения немного сдвинуты в красную сторону от полос поглощения (рис. $1, a)$.

\section{Апконверсия при возбуждении $808,980 \mathrm{~nm}$}

Структура видимых полос свечения при возбуждении 808 и $980 \mathrm{~nm}$ похожа на таковую при возбуждении лазером $405 \mathrm{~nm}$. Наблюдается уменьшение доли зеленой полосы при $550 \mathrm{~nm}$ относительно красной полосы при $600 \mathrm{~nm}$ при переходе от $\mathrm{CaF}_{2}-\mathrm{Er}$ к $\mathrm{SrF}_{2}-\mathrm{Er}$ и $\mathrm{BaF}_{2}-\mathrm{Er}$ (рис. 2). Суммарный цвет свечения кристаллов меняется 
от красного в $\mathrm{CaF}_{2}-\mathrm{Er}$ к зеленому в $\mathrm{BaF}_{2}-\mathrm{Er}$. Можно полагать, что это явление обусловлено зависимостью вероятности многофононных переходов от числа участвующих фононов. Поскольку фононные частоты в ряду $\mathrm{CaF}_{2}-\mathrm{SrF}_{2}-\mathrm{BaF}_{2}$ уменьшаются [12], то увеличивается число фононов, требуемых для безызлучательного переноса с уровня ${ }^{4} S_{3 / 2}$ на нижележащий уровень ${ }^{4} F_{9 / 2}$. Поскольку вероятность многофононного перехода экспоненциально уменьшается с ростом числа фононов от $\mathrm{CaF}_{2}$ к $\mathrm{BaF}_{2}$, то доля красной полосы в общем свечении также уменьшается в этом ряду (рис. 2).

При охлаждении до $80 \mathrm{~K}$ интенсивность красной полосы $660 \mathrm{~nm}$ уменьшается в $1.5-2$ раза, в то время как интенсивность зеленой полосы около $550 \mathrm{~nm}$ увеличивается более чем в 10 раз. Очевидно, причиной этого является „вымораживание“ многофононного перехода ${ }^{4} S_{3 / 2}-{ }^{4} F_{9 / 2}$.

Интенсивность видимых полос свечения в кристаллах $\mathrm{CaF}_{2}-\mathrm{Er}$ квадратично увеличивается с ростом мощности излучения $980 \mathrm{~nm}$ (рис. 3), что указывает на двухфотонный механизм возбуждения (для $\mathrm{BaF}_{2}-\mathrm{Er}$ см. также [4]). Интенсивность видимых полос свечения 540 и $660 \mathrm{~nm}$ в $\mathrm{BaF}_{2}$ квадратично увеличивается с концентрацией эрбия в интервале $0.1-3 \mathrm{~mol} . \%$.

\section{Ап-конверсия при возбуждении $1542 \mathrm{~nm}$}

При возбуждении кристаллов $\mathrm{MeF}_{2}-\mathrm{Er}$ излучением лазера с длиной волны $1542 \mathrm{~nm}$ интенсивность полос свечения 550, 660 и $990 \mathrm{~nm}$ последовательно увеличивается (рис. 4). Соотношение между интенсивностями полос люминесценции при возбуждении лазерами с длинами волн 1542 и $405 \mathrm{~nm}$ отличается. При возбуждении в области $1542 \mathrm{~nm}$ наибольшую интенсивность имеет полоса $990 \mathrm{~nm}$, а наименьшую - полоса с максимумом $550 \mathrm{~nm}$ (рис. 4) При возбуждении $405 \mathrm{~nm}$ различие в интенсивностях значительно меньше (рис. 1). Вклад инфракрасной полосы в общее ап-конверсионное свечение для кристаллов $\mathrm{MeF}_{2}-\mathrm{ErF}_{3}$ составляет более 90\%. Подобный преобладающий вклад инфракрасного свечения $990 \mathrm{~nm}$ в общую ап-конверсию ионов $\mathrm{Er}^{3+}$ при возбуждении $1550 \mathrm{~nm}$ наблюдался также в кристаллах $\mathrm{CaF}_{2}-\mathrm{Y}-\mathrm{Er}[1], \mathrm{CaF}_{2}-\mathrm{Er}, \mathrm{CaF}_{2}-\mathrm{Er}-\mathrm{Yb}$ [8] и стеклах [13].

В простых случаях интенсивность ап-конверсионного свечения растет с мощностью возбуждения как интенсивность возбуждения в степени $n$, где $n=2,3, \ldots$ число фотонов, необходимое для переноса электрона в излучательное состояние.

Интенсивность видимых полос свечения в кристаллах $\mathrm{MeF}_{2}-\mathrm{Er}$ примерно квадратично увеличивается с ростом мощности излучения $1542 \mathrm{~nm}$ (рис. 3), хотя энергетические соотношения указывают на трехфотонный механизм возбуждения. Следует отметить, что коэффициент наклона больше для зеленой $(550 \mathrm{~nm})$ полосы,
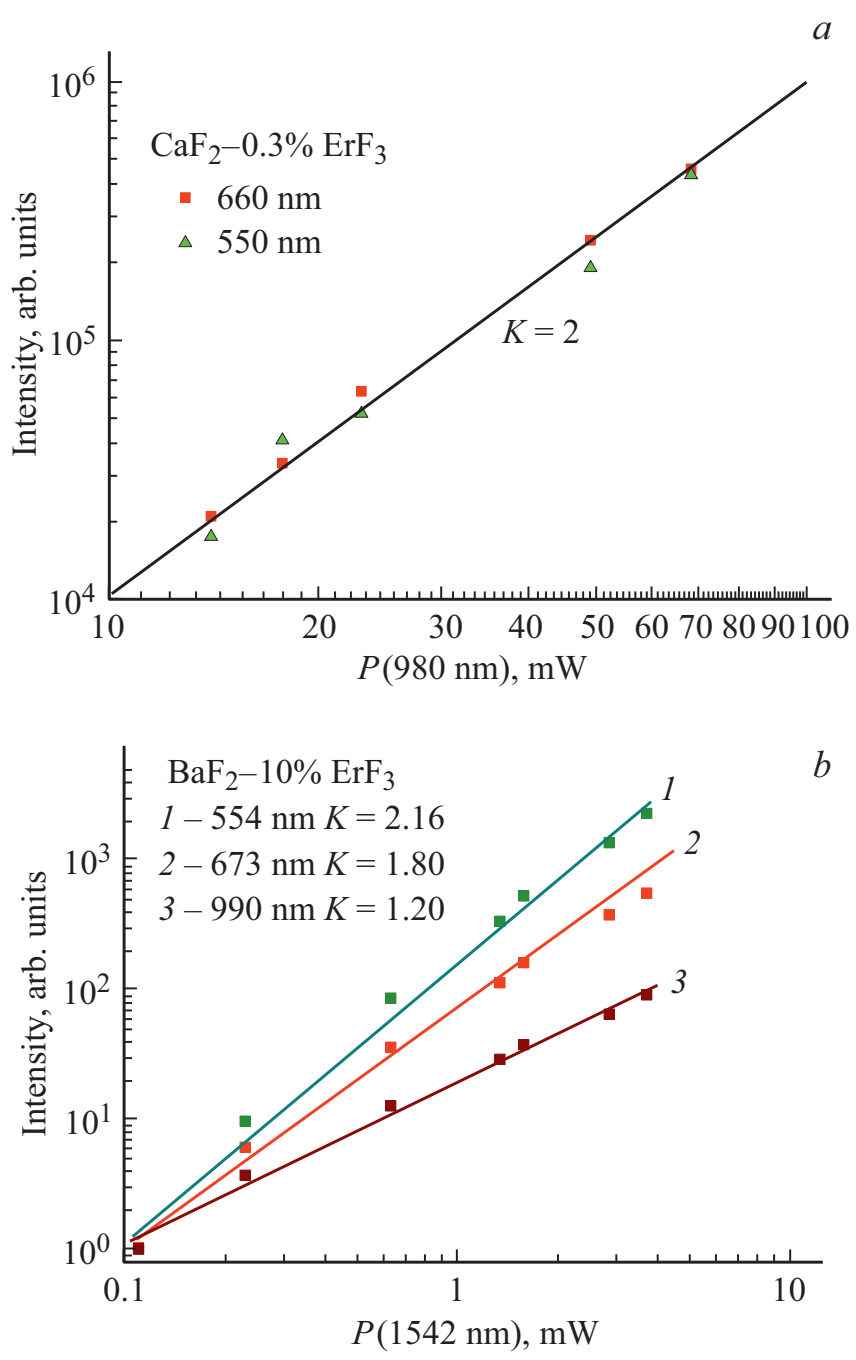

Рис. 3. Зависимость интенсивности видимых полос $\mathrm{CaF}_{2}-\mathrm{ErF}_{3}$ и $\mathrm{BaF}_{2}-\mathrm{ErF}_{3}$ от мощности излучения лазера 980 (a) и $1542 \mathrm{~nm}(b)$. Интенсивность на графике $(b)$ нормирована при малых мощностях для удобного представления, $K-$ степенной показатель зависимости $I=A P^{K}$.

чем для красной полосы $(660 \mathrm{~nm})$. Это приводит к изменению цвета свечения кристаллов $\mathrm{MeF}_{2}-\mathrm{Er}$ от красного к зеленому с увеличением плотности возбуждения. В то же время, коэффициент наклона зависимости для полосы $990 \mathrm{~nm}$ равен 1.2, что меньше 2 - ожидаемого значения, исходя из двухфотонного механизма возбуждения этой полосы.

\section{Выход ап-конверсии}

В общем случае энергетический выход люминофора определяется как отношение излученной мощности к поглощенной $\left(P_{\mathrm{em}} / P_{\mathrm{abs}}\right)$. Для нахождения квантового выхода следует перейти к количеству фотонов в числителе и знаменателе. Поскольку ап-конверсия это нелинейный процесс, ее энергетический выход растет с увеличением 


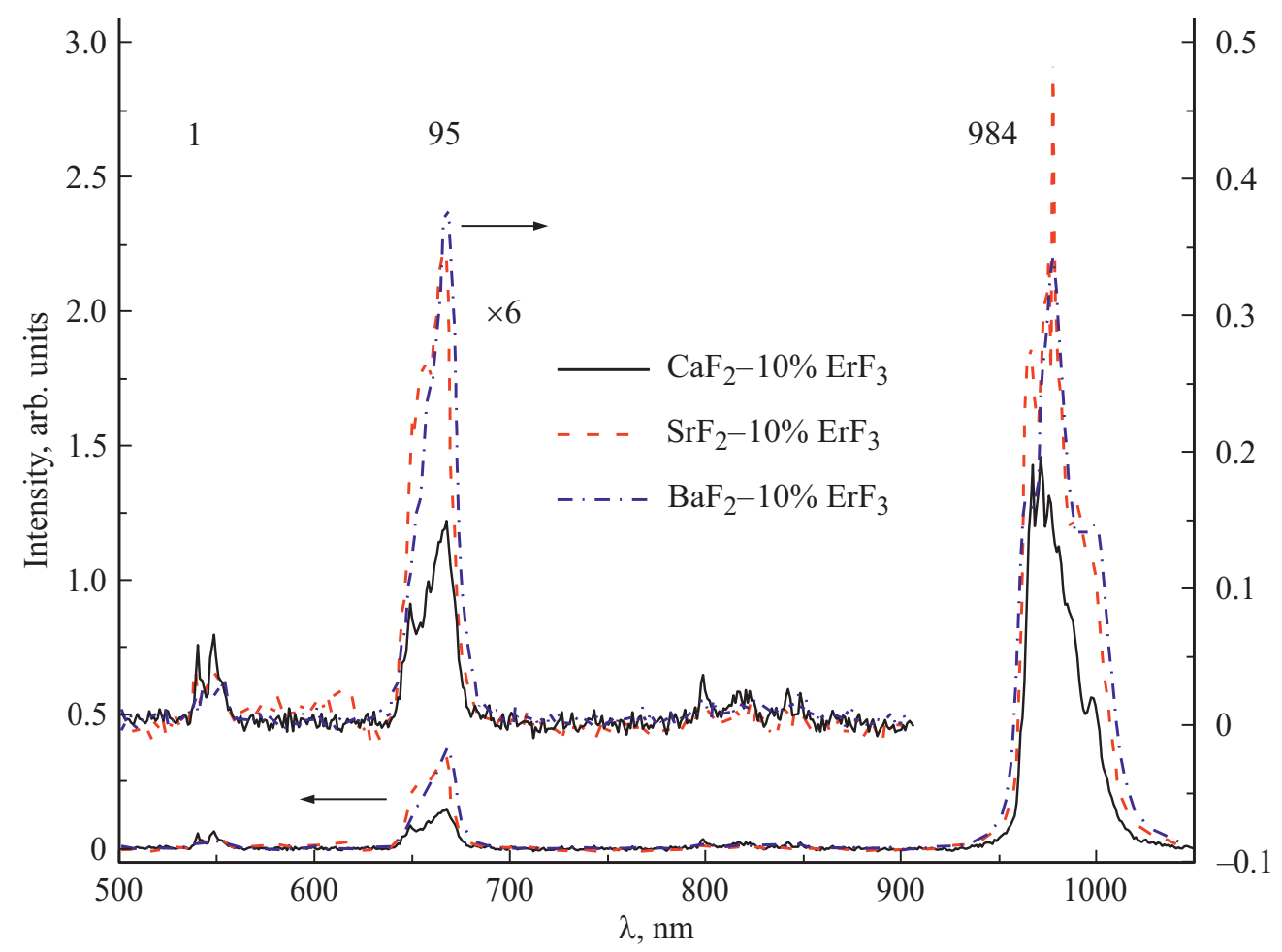

Рис. 4. Спектры свечения кристаллов $\mathrm{MeF}_{2}-10 \% \mathrm{ErF}_{3}$ при возбуждении излучением лазера $1542 \mathrm{~nm}$. Вверху указаны относительные светосуммы полос для $\mathrm{BaF}_{2}-10 \% \mathrm{ErF}_{3}$.

поглощенной мощности. Поэтому для характеристики $n$-фотонной ап-конверсии предложена нормированная эффективность, в которой энергетический выход делится на мощность излучения (или поглощенную мощность) в степени $(n-1)$, что приводит к единицам нормированной эффективности двухфотонного процесса $\mathrm{cm}^{2} / \mathrm{W}$ [2]. В то же время отмечено, что в эффективных порошковых материалах $\mathrm{NaYF}_{4}-\mathrm{Er}, \mathrm{Gd}_{2} \mathrm{O}_{2} \mathrm{~S}-\mathrm{Er}$ интенсивность ап-конверсии выходит на насыщение с ростом мощности излучения, что означает уменьшение нормированной эффективности с ростом мощности [14]. Отклонение показателя степени зависимости выхода ап-конверсии от плотности мощности возбуждения от значения $(n-1)$ наблюдалось также в других работах [9]. Поэтому нормированная эффективность (или выход) ап-конверсии не позволяет однозначно сравнивать эффективности люминофоров между собой. Вследствие этого в публикациях вместе с выходом указывают падающую (или поглощенную) плотность мощности излучения.

Энергетический $N_{e}$ (и квантовый $N_{q}$ ) выход ближнего инфракрасного свечения $990 \mathrm{~nm}$ при возбуждении в области $1550 \mathrm{~nm}$ (таблица) значительно больше выхода видимой ап-конверсии как $\mathrm{MeF}_{2}-\mathrm{Er}$ (рис. 5) так и $\mathrm{MeF}_{2}-\mathrm{Ho}-\mathrm{Yb}$ [10]. Зная энергетический выход, квантовый выход свечения можно определить как $N_{q}=N_{e} h v$ (свечения $) / h v($ возбуждения $)=N_{e} \lambda($ возбуждения)/ $\lambda$ (свечения) (таблица).
Экспериментальные значения для энергетического $\left(N_{e}\right)$ и квантового $\left(N_{q}\right)$ выходов ап-конверсии при возбуждении лазерным диодом $1542 \mathrm{~nm}$ мощностью $5.0 \mathrm{~mW}$ и плотностью мощности сфокусированного пучка $1.2 \mathrm{~W} / \mathrm{cm}^{2}$

\begin{tabular}{c|c|c}
\hline Кристалл & $N_{e}, \%$ & $N_{q}, \%$ \\
\hline $\mathrm{CaF}_{2}-10 \% \mathrm{ErF}_{3}$ & 19.1 & 14.7 \\
$\mathrm{SrF}_{2}-10 \% \mathrm{ErF}_{3}$ & 25.8 & 19.8 \\
$\mathrm{BaF}_{2}-10 \% \mathrm{ErF}_{3}$ & 14.2 & 10.9
\end{tabular}

\section{Обсуждение}

В длинноволновой области наиболее интенсивными переходами в ионах эрбия $\mathrm{Er}^{3+}$ являются переходы из основного состояния на уровни ${ }^{4} I_{13 / 2}(1530 \mathrm{~nm})$ и ${ }^{4} F_{9 / 2}(650 \mathrm{~nm})$ (рис. $1, a$ и $\left.[15]\right)$, тогда как в спектрах фотолюминесценции преобладают переходы с уровней ${ }^{4} I_{13 / 2}(1530 \mathrm{~nm})$ и ${ }^{4} I_{11 / 2}(990 \mathrm{~nm})$ в основное состояние (рис. 1,b).

Энергетические оценки показывают, что для преобразования излучения $1550 \mathrm{~nm}$ в зеленое $550 \mathrm{~nm}$ или красное $660 \mathrm{~nm}$ свечение $\mathrm{Er}^{3+}$ необходимо сложение энергий трех фотонов. Действительно, в кристаллах $\mathrm{CdF}_{2}-\mathrm{Er}^{3+}(4 \%)$ наблюдалась зависимость интенсивности зеленого и красного свечения от мощности излучения $1507 \mathrm{~nm}$ с коэффициентом наклона, близким к 3, эффекты насыщения начинали наблюдаться при плотно- 


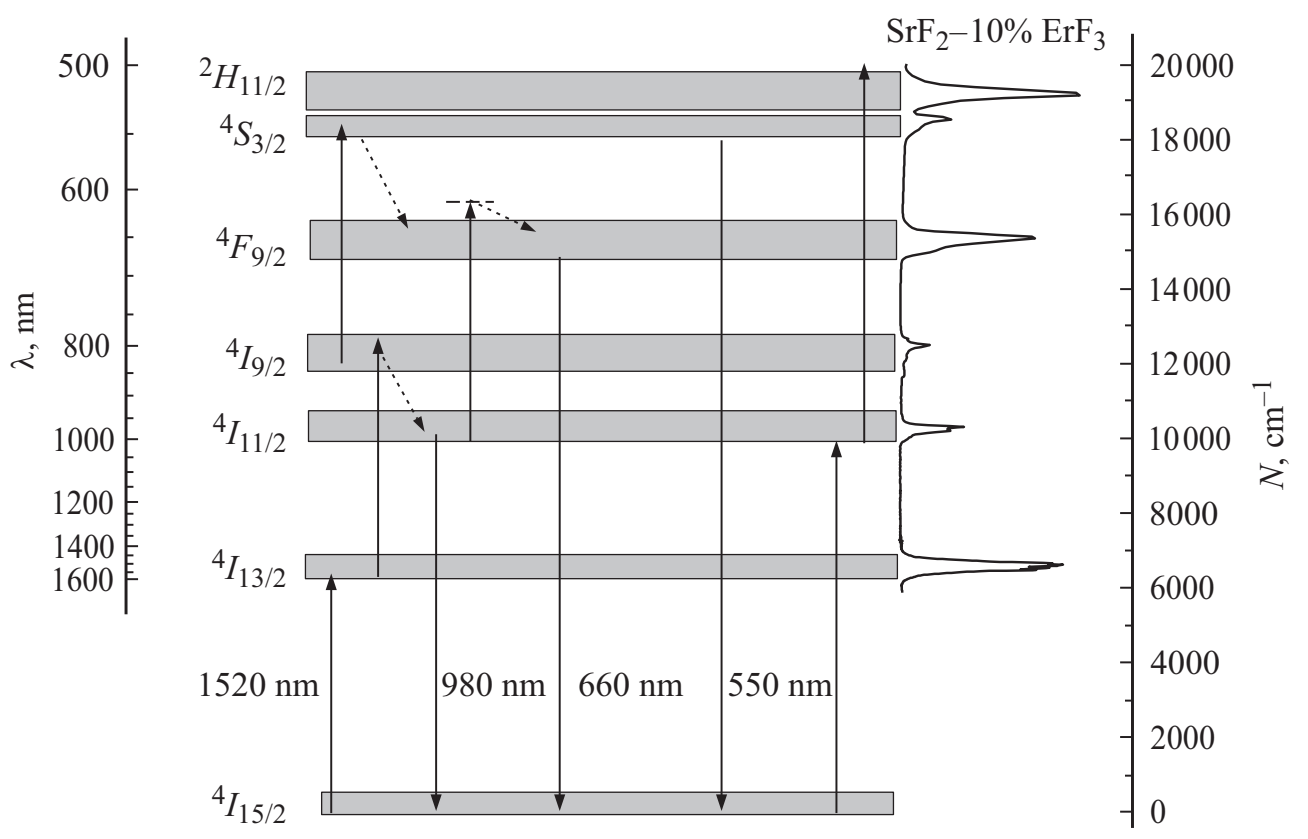

Рис. 5. Схема уровней и оптических переходов в ионах $\mathrm{Er}^{3+}$ в кристаллах $\mathrm{MeF}_{2}$. Возбуждение совершается излучением лазера $1542 \mathrm{~nm}$. Справа приведен спектр поглощения кристалла $\mathrm{SrF}_{2}-\mathrm{Er}$ при комнатной температуре. Схемы ап-конверсионных переходов при поглощении фотонов $1542 \mathrm{~nm}$ [6] указаны слева, при поглощении фотонов $980 \mathrm{~nm}$ - справа.

сти более $1 \mathrm{~W} / \mathrm{cm}^{2}[6]$. В нашем случае при возбуждении $1542 \mathrm{~nm}$ для видимых полос наблюдается зависимость от интенсивности возбуждения с коэффициентом около 2 (рис. 3). Изменение цвета свечения кристалла с зеленоватого на красный хорошо видно глазом при смещении кристалла из фокуса лазерного пучка, когда при увеличении диаметра пучка уменьшается плотность возбуждения. Этот же эффект проявляется в виде разного наклона зависимостей интенсивностей красной и зеленой полос свечения от мощности возбуждения лазера $1542 \mathrm{~nm}$ (рис. $3, b$ ). Изменение цвета свечения и различие показателей степенной зависимости указывают на разные процессы возбуждения двух видимых полос свечения. Этот эффект практически отсутствует при возбуждении $\mathrm{MeF}_{2}-\mathrm{Er}$ лазерами 808 и $980 \mathrm{~nm}$. При охлаждении кристаллов $\mathrm{CaF}_{2}-0.3 \% \mathrm{ErF}_{3}$, возбуждаемых светом $1542 \mathrm{~nm}$, до $80 \mathrm{~K}$ интенсивность зеленой полосы увеличилась в $\sim 2$ раза, а красной полосы - уменьшилась в $\sim 5$ раз. Инфракрасная полоса около $1000 \mathrm{~nm}$ также в несколько раз ослабевает при охлаждении до $80 \mathrm{~K}$. Очевидно, что процесс возбуждения ${ }^{4} F_{9 / 2}-{ }^{4} I_{15 / 2}$ красного свечения включает многофононный перенос ${ }^{4} I_{9 / 2}-{ }^{4} I_{11 / 2}$ электрона вниз (рис. 5), как это предполагается в работах $[6,7]$. Вероятность многофононного переноса электрона сильно уменьшается с понижением температуры кристалла. После такого перехода может произойти излучательный переход ${ }^{4} I_{11 / 2}-{ }^{4} I_{15 / 2}(980 \mathrm{~nm})$ на основное состояние или ап-конверсионный переход вверх ${ }^{4} I_{9 / 2}-{ }^{4} F_{9 / 2}$ и последующее излучение красного свечения. С другой стороны, относительная доля зеленой полосы в $\mathrm{MeF}_{2}$ значительно уменьшается с ростом концентрации $\mathrm{Er}^{3+}$, что, по-видимому, связано с образованием агрегатов $\mathrm{Er}^{3+}$.

Наблюдаемый энергетический выход ап-конверсионного свечения $990 \mathrm{~nm}$ при возбуждении в полосу $1550 \mathrm{~nm}$ весьма высок (таблица), тогда как для видимых полос свечения при возбуждении 980 и $1550 \mathrm{~nm}$ составляет доли процента (рис. 4 и [16]). Высокий выход свечения при $990 \mathrm{~nm}$ позволяет пытаться применить эти материалы для повышения эффективности кремниевых солнечных батарей. Такие исследования для материалов, содержащих $\mathrm{Er}^{3+}$, интенсивно проводятся последние годы $[1,9,14]$. Зависимость прироста тока $\Delta j$ в кремниевом солнечном элементе от интенсивности $C$ инфракрасного излучения солнца, конвертированного в излучение $\sim 980 \mathrm{~nm}$, описывается выражением $\Delta j=a C^{b}$, где коэффициент $b$ равен 1.55 для $\beta-\mathrm{NaYF}_{4}[9]$ и 1.59 для $\mathrm{Gd}_{2} \mathrm{O}_{2} \mathrm{~S}$ [14]. Эти значения, так же как полученный нами коэффициент 1.2 (рис. 3), значительно меньше 2, ожидаемого для двухфотонной ап-конверсии.

\section{Заключение}

Спектр ап-конверсионного свечения $\mathrm{MeF}_{2}-\mathrm{Er}$ при возбуждении светом $1550 \mathrm{~nm}$ имеет сильную полосу при $990 \mathrm{~nm}$, которая составляет более $90 \%$ всего излучения. Высокий энергетический выход ап-конверсии при возбуждении светом $1550 \mathrm{~nm}$ позволяет рассматривать $\mathrm{MeF}_{2}-\mathrm{Er}$ как перспективные люминофоры для повышения чувствительности кремниевых солнечных батарей. 


\section{Благодарности}

В работе использовано оборудование центра коллективного пользования изотопно-геохимических исследований ИГХ СО РАН. Авторы благодарят В.А. Козловского за выращивание кристаллов.

\section{Финансирование работы}

Исследование проведено в рамках выполнения государственного задания по Проекту IX.125.3.2.

\section{Конфликт интересов}

Авторы заявляют, что у них нет конфликта интересов.

\section{Список литературы}

[1] Pellé F., Ivanova S., Guillemoles J.F. // EPJ photovoltaics. 2011. V. 2. P. 20601.

[2] Auzel F. // Chem. Rev. 2004. V. 104. P. 139.

[3] Овсянкин В.В., Феобилов П.П. // Опт. и спектр. 1966. Т. 20. C. 526.

[4] Feofilov P.P., Ovsyankin V.V. // Appl. Opt. 1967. V. 6. P. 1828.

[5] Ovsyankin V.V., Feofilov P.P. // Luminescence of Crystals, Molecules, and Solutions / Ed. by Williams F. et al. N.Y.: Plenum Press, 1973. P. 64-77.

[6] Jouart J.P., Mary G. // J. Luminesc. 1990. V. 46. P. 39.

[7] Jouart J.P., Bisseux C., Mary G. // J. Luminesc. 1984. V. 29. P. 261.

[8] Ivanova S., Pellé F., Tkachuk A. et al. // J. Luminesc. 2008. V. 128. P. 914.

[9] Fischer S., Ivaturi A., Jakobb P. et al. // Opt. Mater. 2018. V. 84. P. 389.

[10] Раджабов Е.А., Шендрик Р.Ю. // Изв. РАН сер. физ. 2019. T. 83. C. 360.

[11] Khosrofian J.M., Garetz B.A. // Appl. Opt.1983. V. 22. P. 3406.

[12] Denham P., Field G.R., Morse P.L.R., Wilkinson G.R. // Proc. Roy. Soc. London A. 1970. V. 317. P. 55.

[13] Ivanova S., Pellé F. // JOSA. B. 2010. V. 27. P. 1356.

[14] Fischer S., Martin-Rodriguez R., Frohlich B. et al. // J. Luminesc. 2014. V. 153. P. 281.

[15] Krupke W.F. // Phys. Rev. 1966. V. 145. P. 325.

[16] Ляпин А.А., Рябочкина П.А., Гущин С.В. и др. // Опт. и спектр. 2018. Т. 125. С. 516. 